Tohoku J. Exp. Med., 2005, 206, 73-80

\title{
Medicolegal Childhood Deaths in Adana, Turkey
}

\author{
Necmi Çekin, Ahmet Hilal, Mete K. Gülmen, Hakan Kar, ${ }^{1}$ Mustafa Aslan ${ }^{1}$ \\ and M. HAKAN ÖZDEMIR ${ }^{2}$ \\ Department of Forensic Medicine, Çukurova University School of Medicine, \\ ${ }^{1}$ Department of Forensic Medicine, Adana Group Administration, and \\ ${ }^{2}$ Department of Forensic Medicine, Dokuz Eylul University School of Medicine, \\ Turkey
}

Çekin, N., Hilal, A., Gülmen, M.K., Kar, H., Aslan, M. and Özdemir, M.H. Medicolegal Childhood Deaths in Adana, Turkey. Tohoku J. Exp. Med., 2005, 206 (1), 73-80

- The objective of this study is to determine the characteristics of and changes in the medicolegal childhood deaths that occurred in the provincial center of Adana, and to contribute to the establishment of a database for the development of national and international policies. The study is a retrospective research examining the 1,110 cases in the age group 0 to 18 , which were specified as medicolegal deaths in the provincial center of AdanaTurkey between the years 2000-2004. The cases were examined according to age, sex, causes of deaths, the origins and scenes of occurrence. Among all the deaths, 523 cases (47.2\%) were seen in the age group of $0-6$ years. Accidents account for 900 cases $(81.1 \%)$, and blunt traumas (594 cases) represent the most common cause of deaths. The share of traffic accidents in total blunt traumas was found to be 441 cases (74.2\%). And 270 (24.3\%) of all medicolegal deaths occured as a result of household accidents. The present study has also indicated that the home and surroundings represent the highest-risk areas. As a conclusion, setting up childhood injury prevention committees and providing training programs for parents will be effective for the prevention of childhood injuries and deaths. medicolegal death; childhood; unintentional injury; preventable death

(C) 2005 Tohoku University Medical Press

Medicolegal deaths in childhood are a significant public health problem all over the world. It can be seen that violent deaths including accidents, homicides and suicides are one of the principal causes of death in childhood (Waller et al. 1989; Christoffel 1990). It has been reported that injury-related childhood deaths, in particular, pose a serious threat to children's health and accounts for $7-10 \%$ of the mortality in the world (Tanaka 1993; Morrison and Stone 1999).

The most important characteristic of child injury deaths is the fact that many, if not most, can be prevented (Wheatley and Cass 1989; Rivara 2002). Saunders et al. (1999) have found that $2.7 \%$ of natural deaths and $96 \%$ of injury deaths are preventable.

It is also emphasized that such injury deaths have reached more alarming levels in developing nations, where technology is being transferred without laying the infrastructural foundations and completing the training programs required for national growth (Soori and Naghavi 1998).

Received November 1, 2004; revision accepted for publication February 21, 2005. Turkey.

Correspondence: Necmi Çekin, Çukurova Üniversitesi Tıp Fakültesi Adli Tıp ABD, 01330 Balcalı, Adana, e-mail: ncekin@cu.edu.tr 
Injury prevention committees have been carefully created in developed nations. It has been suggested in the present study that determining the relationship between injuries and the age group has a major role in the development of national policies and prevention strategies. What is also emphasized in the study is the importance of establishing prevention strategies giving particular attention to local cultural characteristics in reducing the number of childhood injuries and deaths (Vane et al. 1990; Agran et al. 2003). A considerable reduction has been observed in the number of intentional injuries and deaths in studies conducted in Europe within the past 30 years and the declining trend still continues (Morrison and Stone 1999).

The objective of this study is to determine the characteristics of and changes in the medicolegal childhood deaths that occurred in the provincial center of Adana, and to provide contributions to the establishment of a database for the development of national and international policies.

\section{Material ANd Method}

Legal death examination files of Adana public prosecutor's office and the autopsy reports of the Forensic Medicine Institution Adana Group Authority Morgue Specialty Office belonging to the years 2000-2004 were separated into four age groups $(0-6,7-11,12-15,16-18)$ before examination. The separation was carried out according to existing age groups specified in child development and legal practices in our country. These age groups were then examined with respect to sex, cause of death, origin and location of occurrence. Our study field Adana is the 4th largest city of Turkey located in the south of the country. With a population of $1,849,000$, the city has been experiencing significant migration from rural regions (the rate of population increase was $16 \%$ between 1997 and 2000).

\section{Results}

In a period of 5 years (2000-2004), 4,516 medicolegal deaths are investigated in Adana. $1,110(24.6 \%)$ of all cases comprised by our study population were children (0-18 age) (Table 1$)$. $747(67.3 \%)$ of those children were male of gender and 363 (32.7\%) were female. An examina-

TABle 1. Distribution of death cases: cause, age and sex

\begin{tabular}{|c|c|c|c|c|c|c|c|c|c|c|c|}
\hline \multirow{2}{*}{ Causes of deaths / age } & \multicolumn{2}{|c|}{$0-6$} & \multicolumn{2}{|c|}{$7-11$} & \multicolumn{2}{|c|}{$12-15$} & \multicolumn{2}{|c|}{$16-18$} & \multirow{2}{*}{ Total } & \multirow{2}{*}{ M } & \multirow{2}{*}{$\mathrm{F}$} \\
\hline & M & $\mathrm{F}$ & M & $\mathrm{F}$ & M & $\mathrm{F}$ & M & $\mathrm{F}$ & & & \\
\hline Blunt trauma & 174 & 127 & 87 & 43 & 61 & 17 & 69 & 16 & 594 & 391 & 203 \\
\hline Drowning & 26 & 9 & 18 & 3 & 43 & 4 & 33 & 2 & 138 & 120 & 18 \\
\hline Burning & 49 & 45 & 2 & 2 & 6 & 1 & 9 & 0 & 114 & 66 & 48 \\
\hline *Sudden-unexpected & 36 & 23 & 3 & 2 & 3 & 4 & 10 & 6 & 87 & 52 & 35 \\
\hline Firearm & 4 & 2 & 4 & 3 & 6 & 1 & 21 & 5 & 46 & 35 & 11 \\
\hline Intoxication & 4 & 2 & 3 & 0 & 4 & 4 & 6 & 16 & 39 & 17 & 22 \\
\hline Electrocution & 9 & 1 & 6 & 1 & 4 & 0 & 7 & 0 & 28 & 26 & 2 \\
\hline Hanging & 0 & 1 & 1 & 0 & 4 & 4 & 8 & 10 & 28 & 13 & 15 \\
\hline Stabbing & 0 & 0 & 0 & 0 & 2 & 1 & 14 & 4 & 21 & 16 & 5 \\
\hline Aspiration & 6 & 2 & 0 & 0 & 0 & 0 & 0 & 0 & 8 & 6 & 2 \\
\hline Explosion & 1 & 1 & 0 & 1 & 0 & 0 & 2 & 0 & 5 & 3 & 2 \\
\hline Strangulation & 1 & 0 & 0 & 0 & 0 & 0 & 0 & 0 & 1 & 1 & 0 \\
\hline Lightning & 0 & 0 & 0 & 0 & 1 & 0 & 0 & 0 & 1 & 1 & 0 \\
\hline \multirow{2}{*}{ Total } & 310 & 213 & 124 & 55 & 134 & 36 & 179 & 59 & & 747 & 363 \\
\hline & \multicolumn{2}{|c|}{523} & \multicolumn{2}{|c|}{179} & \multicolumn{2}{|c|}{170} & \multicolumn{2}{|c|}{238} & 1,110 & \multicolumn{2}{|c|}{1,110} \\
\hline
\end{tabular}

M, male; F, female.

* The distribution of sudden-unexpected deaths is given for age group. 
tion over distribution of the deaths by age groups and sex revealed that males outnumbered females in all age groups. The highest number of deaths occurred in the 0-6 age group with 523 cases (47.2\%) (Table 1).

The major cause of death of 594 cases $(53.5 \%)$ was blunt trauma. The share of traffic accidents within total blunt trauma deaths was $74.2 \%$ (441 cases) (Table 2). Three hundreds $(68 \%)$ of the children exposed to traffic accidents were pedestrians and 207 (47\%) of the children were in 0-6 age group (Table 2).

Deaths due to indoor accidents were 270 $(24.3 \%)$ within our study population (Table 3 ). Blunt traumas were the leading cause. Ninety six (77\%) of 125 deaths due to indoor blunt trauma were caused by falling down from roof or balconies (Table 3). Indoor burnings succeeded blunt traumas with 101 cases. Ninety four $(93.1 \%)$ of these burning cases were in 0-6 age group and caused by falling into or spilling of boiling liquids.

Irrigation canals were the leading death place with 93 (67.4\%) within 138 deaths due to drowning (Table 4). Basically, drowning occured in boys of 12-18 years old, who originally intended swimming, while falling into the canals in our city as a result of the lack of barriers in the younger ages. Twenty two of the cases drowned in the river passing through our city and 13 cases in the dam lake. Six of the children were found in water depots and waste pits, and 2 cases fell into the washing machine at home. Two cases drowned in the swimming pools (Table 4).

Evaluation of all childhood deaths $(n=1,100)$ revealed that 900 cases $(81.1 \%)$ were caused by accidents, 68 cases $(6.8 \%)$ were suicides (Table 5), 55 cases $(5 \%)$ were homicides (Table 6), and 87

TABLE 2. Blunt trauma deaths: place of occurrence, age and sex

\begin{tabular}{|c|c|c|c|c|c|c|c|c|c|c|c|}
\hline \multirow{2}{*}{ Causes of deaths / age } & \multicolumn{2}{|c|}{$0-6$} & \multicolumn{2}{|c|}{$7-11$} & \multicolumn{2}{|c|}{$12-15$} & \multicolumn{2}{|c|}{$16-18$} & \multirow{2}{*}{ Total } & \multirow{2}{*}{ M } & \multirow{2}{*}{$\mathrm{F}$} \\
\hline & M & $\mathrm{F}$ & M & $\mathrm{F}$ & M & $\mathrm{F}$ & $\mathrm{M}$ & $\mathrm{F}$ & & & \\
\hline \multicolumn{12}{|l|}{ Traffic accidents } \\
\hline Pedestrian & 106 & 72 & 54 & 27 & 21 & 7 & 11 & 2 & 300 & 192 & 108 \\
\hline Inside vehicle & 12 & 10 & 11 & 9 & 10 & 5 & 24 & 5 & 86 & 57 & 29 \\
\hline Bicycle-motorcyle & 1 & 0 & 4 & 1 & 15 & 1 & 17 & 0 & 39 & 37 & 2 \\
\hline Train accidents & 2 & 4 & 2 & 1 & 3 & 0 & 3 & 1 & 16 & 10 & 6 \\
\hline Total & \multicolumn{2}{|c|}{207} & \multicolumn{2}{|c|}{109} & \multicolumn{2}{|c|}{62} & \multicolumn{2}{|c|}{63} & & \multicolumn{2}{|c|}{441} \\
\hline \multicolumn{12}{|l|}{ Falling } \\
\hline Roof-balcony & 37 & 28 & 11 & 2 & 8 & 3 & 3 & 4 & 96 & 59 & 37 \\
\hline Indoor & 12 & 9 & 1 & 2 & 0 & 0 & 0 & 0 & 24 & 13 & 11 \\
\hline Crush at home & 2 & 1 & 2 & 0 & 0 & 0 & 0 & 0 & 5 & 4 & 1 \\
\hline Total & \multicolumn{2}{|c|}{89} & \multicolumn{2}{|c|}{18} & \multicolumn{2}{|c|}{11} & \multicolumn{2}{|c|}{7} & & \multicolumn{2}{|c|}{125} \\
\hline Falling outdoors & 2 & 2 & 2 & 1 & 2 & 0 & 7 & 1 & 17 & 13 & 4 \\
\hline Total & \multicolumn{2}{|c|}{4} & \multicolumn{2}{|c|}{3} & \multicolumn{2}{|c|}{2} & \multicolumn{2}{|c|}{8} & & \multicolumn{2}{|c|}{17} \\
\hline Jumping & 0 & 0 & 0 & 0 & 0 & 1 & 1 & 3 & 5 & 1 & 4 \\
\hline Total & \multicolumn{2}{|c|}{0} & \multicolumn{2}{|c|}{0} & \multicolumn{2}{|c|}{1} & \multicolumn{2}{|c|}{4} & & \multicolumn{2}{|c|}{5} \\
\hline Beating & 0 & 1 & 0 & 0 & 2 & 0 & 3 & 0 & 6 & 5 & 1 \\
\hline Total & \multicolumn{2}{|c|}{1} & \multicolumn{2}{|c|}{0} & \multicolumn{2}{|c|}{2} & & & & & \\
\hline & 174 & 127 & 87 & 43 & 61 & 17 & 69 & 16 & & 391 & 203 \\
\hline Total & & & & & & & & & 594 & & \\
\hline
\end{tabular}


N. Çekin et al.

TABLE 3. Accidental deaths at the home: cause, age and sex

\begin{tabular}{|c|c|c|c|c|c|c|c|c|c|c|c|}
\hline \multirow{2}{*}{ Causes of deaths / age } & \multicolumn{2}{|c|}{$0-6$} & \multicolumn{2}{|c|}{$7-11$} & \multicolumn{2}{|c|}{$12-15$} & \multicolumn{2}{|c|}{$16-18$} & \multirow{2}{*}{ Total } & \multirow{2}{*}{ M } & \multirow{2}{*}{$\mathrm{F}$} \\
\hline & M & $\mathrm{F}$ & $\mathrm{M}$ & $\mathrm{F}$ & M & $\mathrm{F}$ & M & $\mathrm{F}$ & & & \\
\hline Blunt trauma & 51 & 38 & 14 & 4 & 8 & 3 & 3 & 4 & 125 & 76 & 49 \\
\hline Burning & 49 & 45 & 1 & 2 & 1 & 1 & 2 & 0 & 101 & 53 & 48 \\
\hline Electrocution & 9 & 1 & 4 & 0 & 1 & 0 & 4 & 0 & 19 & 18 & 1 \\
\hline Drowning & 3 & 4 & 0 & 0 & 0 & 0 & 0 & 1 & 8 & 3 & 5 \\
\hline Intoxiation & 4 & 1 & 1 & 0 & 0 & 1 & 1 & 0 & 8 & 6 & 2 \\
\hline Firearm & 2 & 1 & 1 & 1 & 0 & 0 & 0 & 0 & 5 & 3 & 2 \\
\hline Aspiration & 3 & 1 & 0 & 0 & 0 & 0 & 0 & 0 & 4 & 3 & 1 \\
\hline \multirow{2}{*}{ Total } & 121 & 91 & 21 & 7 & 10 & 5 & 10 & 5 & & 162 & 108 \\
\hline & \multicolumn{2}{|c|}{212} & \multicolumn{2}{|c|}{28} & & & \multicolumn{2}{|c|}{15} & 270 & \multicolumn{2}{|c|}{270} \\
\hline
\end{tabular}

TABLe 4. Distribution of death place in drowning cases

\begin{tabular}{|c|c|c|c|c|c|c|c|c|c|c|c|}
\hline \multirow{2}{*}{ Location / age } & \multicolumn{2}{|c|}{$0-6$} & \multicolumn{2}{|c|}{$7-11$} & \multicolumn{2}{|c|}{$12-15$} & \multicolumn{2}{|c|}{$16-18$} & \multirow{2}{*}{ Total } & \multirow{2}{*}{ M } & \multirow{2}{*}{$\mathrm{F}$} \\
\hline & M & $\mathrm{F}$ & M & $\mathrm{F}$ & M & $\mathrm{F}$ & M & $\mathrm{F}$ & & & \\
\hline Canal & 18 & 4 & 13 & 1 & 34 & 1 & 22 & 0 & 93 & 87 & 6 \\
\hline River & 4 & 0 & 2 & 1 & 7 & 2 & 4 & 2 & 22 & 17 & 5 \\
\hline Dam lake & 0 & 0 & 3 & 1 & 2 & 1 & 6 & 0 & 13 & 11 & 2 \\
\hline Evde & 4 & 4 & 0 & 0 & 0 & 0 & 0 & 0 & 8 & 4 & 4 \\
\hline Swimming pool & 0 & 1 & 0 & 0 & 0 & 0 & 1 & 0 & 2 & 1 & 1 \\
\hline \multirow{2}{*}{ Total } & 26 & 9 & 18 & 3 & 43 & 4 & 33 & 2 & 120 & 120 & 18 \\
\hline & \multicolumn{2}{|c|}{35} & \multicolumn{2}{|c|}{21} & \multicolumn{2}{|c|}{47} & \multicolumn{2}{|c|}{35} & 138 & \multicolumn{2}{|c|}{138} \\
\hline
\end{tabular}

TABLE 5. Suicides: cause, age and sex

\begin{tabular}{|c|c|c|c|c|c|c|c|c|c|c|c|}
\hline \multirow{2}{*}{ Causes of deaths / age } & \multicolumn{2}{|c|}{$0-6$} & \multicolumn{2}{|c|}{$7-11$} & \multicolumn{2}{|c|}{$12-15$} & \multicolumn{2}{|c|}{$16-18$} & \multirow{2}{*}{ Total } & \multirow{2}{*}{ M } & \multirow{2}{*}{$\mathrm{F}$} \\
\hline & M & $\mathrm{F}$ & M & $\mathrm{F}$ & M & $\mathrm{F}$ & M & $\mathrm{F}$ & & & \\
\hline Hanging & 0 & 0 & 1 & 0 & 4 & 4 & 8 & 10 & 27 & 13 & 14 \\
\hline Intoxiation & 0 & 0 & 0 & 0 & 1 & 6 & 3 & 9 & 19 & 4 & 15 \\
\hline Firearm & 0 & 0 & 0 & 0 & 0 & 1 & 7 & 4 & 12 & 7 & 5 \\
\hline Jumping & 0 & 0 & 0 & 0 & 0 & 1 & 1 & 3 & 5 & 1 & 4 \\
\hline Burning & 0 & 0 & 0 & 0 & 0 & 0 & 3 & 0 & 3 & 3 & 0 \\
\hline Drowning & 0 & 0 & 0 & 0 & 0 & 1 & 1 & 0 & 2 & 1 & 1 \\
\hline \multirow{2}{*}{ Total } & 0 & 0 & 1 & 0 & 5 & 13 & 23 & 26 & & 29 & 39 \\
\hline & \multicolumn{2}{|c|}{0} & \multicolumn{2}{|c|}{1} & \multicolumn{2}{|c|}{18} & \multicolumn{2}{|c|}{49} & 68 & \multicolumn{2}{|c|}{68} \\
\hline
\end{tabular}

cases $(7.8 \%)$ were sudden-unexpected (Table 7).

Of 68 suicides, $27(39.7 \%)$ cases were due to hanging, and $19(27.9 \%)$ were due to intoxication. $49(72.1 \%)$ of the total suicide cases were from
16-18 age group (Table 5). Of all intoxication cases, 15 were from 12-18 age group of females. $12(80 \%)$ of these 15 cases ingested pesticides whereas the rest used medications. 
Why Do Children Die?

TABLE 6. Homicides: cause, age and sex

\begin{tabular}{|c|c|c|c|c|c|c|c|c|c|c|c|}
\hline \multirow{2}{*}{ Causes of deaths / age } & \multicolumn{2}{|c|}{$0-6$} & \multicolumn{2}{|c|}{$7-11$} & \multicolumn{2}{|c|}{$12-15$} & \multicolumn{2}{|c|}{$16-18$} & \multirow{2}{*}{ Total } & \multirow{2}{*}{ M } & \multirow{2}{*}{$\mathrm{F}$} \\
\hline & M & $\mathrm{F}$ & M & $\mathrm{F}$ & M & $\mathrm{F}$ & M & $\mathrm{F}$ & & & \\
\hline Firearm & 2 & 1 & 2 & 1 & 5 & 0 & 14 & 1 & 26 & 23 & 3 \\
\hline Stabbing & 0 & 0 & 0 & 0 & 1 & 1 & 14 & 4 & 20 & 15 & 5 \\
\hline Beating & 0 & 1 & 0 & 0 & 2 & 0 & 3 & 0 & 6 & 5 & 1 \\
\hline Burning & 0 & 0 & 2 & 0 & 0 & 0 & 0 & 0 & 2 & 2 & ( \\
\hline Strangulation & 1 & 0 & 0 & 0 & 0 & 0 & 0 & 0 & 1 & 1 & c \\
\hline \multirow{2}{*}{ Total } & 3 & 2 & 4 & 1 & 8 & 1 & 31 & 5 & & 46 & S \\
\hline & \multicolumn{2}{|c|}{5} & \multicolumn{2}{|c|}{5} & \multicolumn{2}{|c|}{9} & \multicolumn{2}{|c|}{36} & 55 & \multicolumn{2}{|c|}{55} \\
\hline
\end{tabular}

TABLE 7. Causes of deaths in sudden-unexpected death cases

\begin{tabular}{|c|c|c|c|c|c|c|c|c|c|c|c|}
\hline \multirow{2}{*}{ Causes of deaths / age } & \multicolumn{2}{|c|}{$0-6$} & \multicolumn{2}{|c|}{$7-11$} & \multicolumn{2}{|c|}{$12-15$} & \multicolumn{2}{|c|}{$16-18$} & \multirow{2}{*}{ Total } & \multirow{2}{*}{ M } & \multirow{2}{*}{$\mathrm{F}$} \\
\hline & M & $\mathrm{F}$ & M & $\mathrm{F}$ & M & $\mathrm{F}$ & M & $\mathrm{F}$ & & & \\
\hline Infection & 25 & 15 & 3 & 2 & 1 & 0 & 2 & 1 & 49 & 31 & 18 \\
\hline Unidentified & 7 & 3 & 0 & 0 & 1 & 0 & 2 & 1 & 14 & 10 & 4 \\
\hline Cardiovascular & 0 & 1 & 0 & 0 & 0 & 1 & 5 & 2 & 9 & 5 & 4 \\
\hline Nervous system & 1 & 1 & 0 & 0 & 1 & 2 & 0 & 2 & 7 & 2 & 5 \\
\hline Gastrointestinal & 1 & 2 & 0 & 0 & 0 & 1 & 1 & 0 & 5 & 2 & 3 \\
\hline Malignancy & 1 & 1 & 0 & 0 & 0 & 0 & 0 & 0 & 2 & 1 & 1 \\
\hline Hemostatic disease & 1 & 0 & 0 & 0 & 0 & 0 & 0 & 0 & 1 & 1 & 0 \\
\hline \multirow{2}{*}{ Total } & 36 & 23 & 3 & 2 & 3 & 4 & 10 & 6 & & 52 & 35 \\
\hline & \multicolumn{2}{|c|}{59} & \multicolumn{2}{|c|}{5} & \multicolumn{2}{|c|}{7} & \multicolumn{2}{|c|}{16} & 87 & \multicolumn{2}{|c|}{87} \\
\hline
\end{tabular}

Of 55 homicides in childhood, $26(47.3 \%)$ cases were associated with firearms and 20 $(36.4 \%)$ with stabbing. Eighteen $(90 \%)$ of the stabbing cases were in 16-18 age group (Table 6).

Infectious diseases account for $56.3 \%$ (49 cases) of the 87 cases that were determined as sudden-unexpected deaths. 0-6 age group takes the biggest share with a number of $59(67.8 \%)$ in all sudden-unexpected deaths cases (Table 7).

\section{Discussion}

It has been reported that childhood injuries and deaths mostly occur in the first five years, starting in the 3-5th months of life, peaking in the 15-17th months, and declining towards the 42-44th months (Agran et al. 2003). Mobility acquired by means of walking, failure to perceive changes and inability to protect oneself present serious injury risks for a child in this age group (0-5 years) (Hall et al. 1989; Bannon et al. 1992). In our study as well, 47.2 of childhood injuries and deaths occurred in the 0-6 age group.

It has been stated that a substantial part of childhood injuries and deaths occur in the home and in the immediate surroundings (within about 2 kilometers of the home). Homes, places where an environment of highest safety and support is expected to be provided for the child, has unfortunately, become areas with most serious risks, as far as childhood injuries and deaths are concerned. Leading causes of injuries occurring in the home or in the immediate surroundings include traffic accidents, falls, electrocution and drowning (Gardiner et al. 1985).

Examination of the related literature has revealed that falls are an important segment within 
the overall home accident picture. Falling while playing games or falling off the furniture generally accounts for a great portion of the falls in the home. In our study, 125 (46.3\%) of the blunt trauma deaths occurred at home. Falling off the roof or the balcony was responsible for $(76.8 \%)$ of the deaths resulting from falls. This is attributed to the local characteristics of the province of south and southeast cities of our country. Falling off roofs and balconies stems from the fact that family members, including children, tend to sleep on roofs and balconies without banisters and barriers in order to alleviate the intense heat and humidity in this part of the Turkey in summer months (Gören et al. 2003a).

Burns and scalds are also significant in childhood home injuries. In the literature, burns and scalds are usually seen as accidents involving the child falling into a container full of hot liquid or being scalded with very hot liquid (Türegün 1997). Of the 114 childhood burn deaths our study, $101(88.6 \%)$ occurred in the home. All of the 94 cases were in the 0-6 age group and resulted from accidentally coming in contact with hot liquid.

Traffic accidents have been reported as a leading cause of childhood deaths (except for the first year). It has been indicated that especially children left unattended are under great risk. In studies conducted in different parts of our country, traffic accidents occupy the top place among the medicolegal deaths in all age groups (Gürses et al. 2003). Similarly, traffic accidents constituted the largest group among blunt trauma injuries in our study too. In $68 \%$ of the 441 traffic accidents, the victims were pedestrians.

Drowning accounted for a great portion of deaths occurring in childhood. In a study carried out in Austria, the share of drowned children who were aged less than five years at home deaths has been reported as 46\% (Wheatley and Cass 1989). An important portion of drowning cases occur in the family pool. It has been indicated that allowing the child near or inside the water, unattended, and failing to secure the sides of the pool with barriers are the leading risks threatening a child's life (Stevenson et al. 2003). Drowning accounts for a great share in our series also. However, they differ from the literature as for the place of occurrence. $67.4 \%$ of our victims were drowned in watering canals. The incidents occurred when victims fell into the watering canals passing through the residential areas of the city or when children in the 12-18 age group got into these canals to swim.

It has been reported that as the victim's age goes over 15, the number of cases that are of homicidal origin also increases (Fornes et al. 1995). Firearms are a predominant factor among the homicides in the studies carried out (Gören et al. 2003b). In addition, major traumas, strangling, stabbings, poisonings and drowning are frequently encountered. Highlighting the fact that a great many homicides are committed in the home using a weapon kept in the house. it has been made very clear that keeping a weapon in the house presents a more serious risk for the family members, rather than providing protection for them (Kellerman and Reay 1986). In our study, childhood deaths of homicidal origin account for 5\% of the total. Correlating to prevailing knowledge and a former study performed in our region, firearms took the first place as the cause of death and stabbing succeeded this.

Although suicides are rarely seen in smaller age groups and early adolescence, it presents a growing risk in older age groups. Therefore, preventing suicides in adolescence has become the main concern (Pelkonen and Marttunen 2003). The leading cause of death in suicides was hanging and drugs in childhood. Fourty nine of our 68 suicide cases were in the 16-18 age groups. The youngest victim that was recorded in our study was a 11-year-old male. Significant portion of intoxication cases were females and in $80 \%$ of them pesticide ingestion was the cause of death. Extensive use of pesticides stems not only from the location of the province within an agricultural region, but also from the habit of keeping these chemicals in the house and within reach of family members.

It has been stated that leading causes of death are infectious and undetermined diseases during the first 4 year of life, and cardiovascular 
and central nervous system diseases between the ages of 14 and 21 (Neuspiel and Kuller 1985). Similarly, in our study, deaths due to infectious diseases took the first place and undetermined deaths came after among the whole death causes in 0-6 age group. In 12-18 age group cardiovascular and central nerve system diseases were the foremost causes.

Research studies have been indicating a decline in the number of intentional injuries especially in the European countries. This pleasing improvement, however, is said to be overshadowed by the increase observed in the number of homicides and suicides (Michaud 1983; Saunders et al. 1999). A comparison between a study we carried out 10 years ago on childhood age groups (Salaçin et al. 1994) and a percent data exhibits a $30 \%$ decline in the number of medicolegal child deaths. It was also observed that the share of childhood deaths in overall medicolegal deaths dropped to $28 \%$ from a previous rate of $33.6 \%$. What has actually caused that decline in the number of medicolegal deaths in childhood is not known at this time. However, the decline in the number of legal cases despite a high birth-rate in our province, the increase in the population and massive migration from other regions of the country is quite remarkable (the rate of population increase in the province was $29.64 \%$ between 1990 and 2000). The sharpest drop in the number of intentional injuries was observed in burns and scalds $(59 \%)$, followed by drowning and electric shocks by half and traffic accidents (30\%). It was seen that there was no significant change in intoxications and hangings. There was also a $30 \%$ decrease in cases involving the use of firearms and stabbing, $24 \%$ in suicides and $19 \%$ in traffic accidents.

\section{Conclusion}

Childhood deaths, especially intentional injury cases, enhance the liability of those who are responsible for the care and supervision of children. Although this liability is basically attributed to the parents, it concerns all institutions and officials that are assigned to provide a safe and healthy environment for children.
Developing national policies in accordance with regional characteristics, setting up childhood injury prevention committees, and providing training programs that would inform the parents for potential hazards will greatly contribute to the prevention of childhood injuries and deaths.

\section{References}

Agran, P.F., Anderson, C., Winn, D., Trent, R., Walton-Haynes, L. \& Thayer, S. (2003) Rates of pediatric injuries by 3 -month intervals for children 0 to 3 years of age. Pediatrics, 111, 683-692.

Bannon, M.J., Carter, Y.H. \& Mason, K.T. (1992) Causes of fatal childhood accidents in North Staffordshire, 1980-1989. Arch. Emerg. Med., 9, 357-366.

Christoffel, K.K. (1990) Violent death and injury in US children and adolescents. Am. J. Dis. Child., 144, 697-706.

Fornes, P., Druilhe, L. \& Lecomte, D. (1995) Childhood homicide in Paris, 1990-1993: a report of 81 cases. J. Forensic Sci., 40, 201-204.

Gardiner, S.D., Smeeton, W.M., Koelmeyer, T.D. \& Cairns, F.J. (1985) Accidental drownings in Auckland children. N. Z. Med. J., 98, 579-582.

Gören, S., Subaşı, M., Tıraşcı, Y. \& Kemaloğlu, S. (2003a) Firearm-related mortality: a review of four hundred-forty four deaths in Diyarbakır, Turkey between 1996 and 2001. Tohoku J. Exp. Med., 201, 139-145.

Gören, S., Subaşı, M., Tıraşcı, Y. \& Gürkan, F. (2003b) Fatal Falls from Heights in and around Diyarbakır, Turkey. Forensic Sci. Int., 137, 37-40.

Gürses, D., Sarığlu-Buke, A., Başkan, M. \& Kılıç İ. (2003) Cost factors in pediatric trauma. Can. J. Surg., 46, 441-445.

Hall, J.R., Reyes, H.M., Horvat, M., Meller, J.L. \& Stein, R. (1989) The mortality of childhood falls. J. Trauma, 29, 1273-1275.

Kellermann, A.L. \& Reay, D.T. (1986) Protection or peril? An analysis of firearm-related deaths in the home. N. Engl. J. Med., 314, 1557-60.

Michaud, P.A. (1983) Violent deaths among adolescents in Switzerland. From epidemiology to prevention. Pediatrician, 12, 28-36.

Morrison, A., Stone, D.H. \& EURORISC Working Group (1999) Unintentional childhood injury mortality in Europe 1984-93: a report from the EURORISC Working Group. Inj. Prev., 5, 171-176.

Neuspiel, D.R. \& Kuller, L.H. (1985) Sudden and unexpected natural death in childhood and adolescence. JAMA, 254, 1321-1325.

Pelkonen, M. \& Marttunen, M. (2003) Child and adolescent suicide: epidemiology, risk factors, and approaches to prevention. Paediatr. Drugs, 5, 243-265.

Rivara, F.P. (2002) Prevention of injuries to children and adolescents. Inj. Prev., 8, 5-8.

Salaçin, S., Çekin, N., Gülmen, M.K., Özdemir, M.H. \& Şen, F. (1994) Childhood death in Adana. 1. National Forensic Medicine Congress' Book, 23-28. (in Turkish)

Saunders, C.O., Forjuoh, S.N., West, P. \& Brooks, C. (1999) Child death reviews: a gold mine for injury prevention and control. Inj. Prev., 5, 276-279.

Soori, H. \& Naghavi, M. (1998) Childhood deaths from unin- 
tentional injuries in rural areas of Iran. Inj. Prev., 4 222-224.

Stevenson, M.R., Rimajova, M., Edgecombe, D. \& Vickery, K. (2003) Childhood drowning: Barriers surrounding private swimming pools. Pediatrics, 111, 115-119.

Tanaka, T. (1993) Childhood injuries in Japan. Acta Paediatr. Jpn., 35, 179-185.

Türegün, M. (1997) An extraordinary cause of scalding injury in childhood. Burns, 23, 170-173.
Vane, D., Shedd, F.G., Grosfeld, J.L., Franiak, R.J., Ulrich, J.C., West, K.W. \& Rescorla, F.J. (1990) An analysis of pediatric trauma deaths in Indiana. J. Pediatr. Surg., 25, 955-960.

Waller, A.E., Baker, S.P. \& Szocka, A. (1989) Childhood injury deaths: national analysis and geographic variations. Am.J. Public. Health, 79, 310-315.

Wheatley, J. \& Cass, D.T. (1989) Traumatic deaths in children: the importance of prevention. Med.J. Aust., 150, 72-78. 